Brensing, Alexander; Hauck, Stefan; Ruff, Roman; Poppendieck, Wigand; Hoffmann, Klaus-Peter:

Comparison of different conductive fillers in silicone for the purpose of replacing metallic conductive structures in flexible implants

Zuerst erschienen in: Biomedical Engineering = Biomedizinische Technik. - Berlin [u.a.] : de Gruyter. - 58 (2013), Suppl. 1, Track-O, art. [4382], 2 pp.

Erstveröffentlichung: $\quad$ 2013-09-07

ISSN (online): $\quad$ 1862-278X

ISSN (print): $\quad$ 0013-5585

DOI: $\quad 10.1515 /$ bmt-2013-4382

[Zuletzt gesehen: 2019-07-19]

„Im Rahmen der hochschulweiten Open-Access-Strategie für die Zweitveröffentlichung identifiziert durch die Universitätsbibliothek IImenau. “

"Within the academic Open Access Strategy identified for deposition by IImenau University Library."

„Dieser Beitrag ist mit Zustimmung des Rechteinhabers aufgrund einer (DFGgeförderten) Allianz- bzw. Nationallizenz frei zugänglich."

"This publication is with permission of the rights owner freely accessible due to an Alliance licence and a national licence (funded by the DFG, German

Research Foundation) respectively." 


\title{
Comparison of different conductive fillers in silicone for the purpose of replacing metallic conductive structures in flexible implants
}

\author{
Brensing, A. ${ }^{1}$, Hauck, S. ${ }^{2}$, Ruff, R. ${ }^{1}$, Poppendieck, W. ${ }^{1}$, Hoffmann, K.-P. ${ }^{1}$ \\ ${ }^{1}$ Fraunhofer Institute for Biomedical Engineering IBMT, St. Ingbert, Germany \\ ${ }^{2}$ Ilmenau University of Technology, Ilmenau, Germany \\ alexander.brensing@ibmt.fraunhofer.de
}

\begin{abstract}
Graphite (G), Carbon Black (CB) and Carbon Nanotubes (CNT) are compared regarding their usability as conductive filling particles in medical silicone. Produced test structures were characterized mechanically and electrically. CNT turn out to produce the lowest electrical resistance at the lowest concentration. This and the small elongation dependency of the test structure resistance at lengthening up to $6 \%$ cause CNT to be the ideal filler. Therefore CNT filled silicone is the best choice to replace metallic conductive structures in flexible implants.
\end{abstract}

Keywords: silicone, electrical functionalization, Carbon Black, Graphite, Carbon Nano Tubes

\section{Introduction}

Many efforts were made to manufacture flexible implants [1]-[4]. Usually metallic conductive tracks are used because of their good conductivity. Meander conducting paths are used to achieve stretchable implants. However, due to the different mechanical properties of metal and the flexible substrate mechanical stress arises at the occurrence of tensile strain and thereby it is possible that the implant is damaged. One approach to overcome this problem is the use of all polymer technology, replacing the metals with conductive polymers [5], [6].

In this work we compare different conductive filling materials that can be used for electrical functionalization of Polydimethylsiloxane (PDMS).

\section{Methods}

For preparation of the conducting polymers, Nusil Med 6015 was used as polymeric host matrix. Using a speed mixer, conductive particles were intermixed. As filling materials we used 10, 20 and $30 \mathrm{wt} \% \mathrm{CB}$ (LUH GmbH), 20, 36, 40 and $45 \mathrm{wt} \% \mathrm{G}(\mathrm{LUH} \mathrm{GmbH})$ and 2, 3.5 and $5 \mathrm{wt} \%$ multi walled CNT (Sigma Aldrich Chemie GmbH).

To compare the different materials, the electrical and mechanical properties are of interest. Experiments were done with test structures that were designed based on the German standard DIN 53504:2009 (ICS 83.060) [7] (length $75 \mathrm{~mm}$, width $4 \mathrm{~mm}$, thickness $2 \mathrm{~mm}$ ) as shown in Figure 1 .

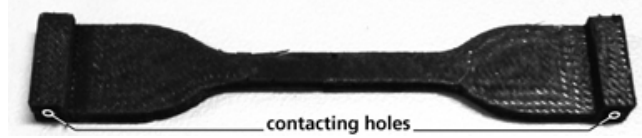

Figure 1: Tensile test structure with contacting holes for electrical and mechanical characterization of filled polymers
Both electrical resistance and the lengthening of the test structure were measured simultaneously. Measurements were repeated at least 15 times for each test structure. For this purpose a special test site was constructed and evaluated, which can automatically measure the specific electric resistance as a function of the mechanical tension. The decrease of the cross-sectional area can be calculated via optical measurement of the sample relief at elongation.

With a 3D printer (Stratasys Dimension Elite), special clamps were built to hold the test structures and contact them for the measurement of different resistance values. The contact to the current supply was applied with two single metallic plugs that are put in the intended hole in the test structure.

\section{Results}

Figure 2 shows a comparison between G, CB and CNT, each at the highest concentration possible to produce test structures. The viscosity of polymers with higher particle concentrations was too high to produce test structures without large air bubbles. The resistance was measured over the entire test structure.

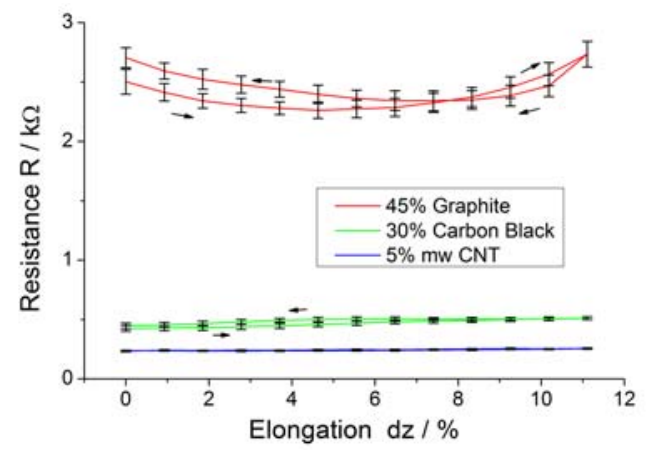

Figure 2: Resistance as function of the test structure elongation. Comparison of different conducting fillers each at the highest concentration.

Remarkable is the different behavior of $\mathrm{G}$ and $\mathrm{CB}$ for different elongations. For visualization Figure 3 compares both at the same resistance, because $\mathrm{CB}$ filled test structures behaved similarly for different $\mathrm{CB}$ concentrations. While the $\mathrm{CB}$ filled test structure exhibited an almost constant increase of the resistance at elongation up to $11 \%$, the resistance of the $\mathrm{G}$ filled polymer decreased up to an elongation of $6 \%$. For further stretching up to $11 \%$ the resistance reached its starting value. Both composites possessed a hysteresis behavior. 
During lengthening, the resistance of the $\mathrm{CB}$ filled test structures was lower than during relaxation. The $G$ filled structures behaved similarly up to an elongation of about $8 \%$. For higher elongations the resistance during lengthening was higher than during relaxation.

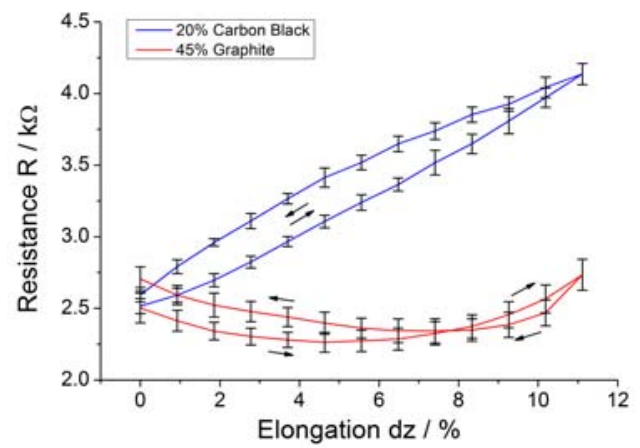

Figure 3: Comparison of the behavior of Graphite and Carbon Black as conducting fillers in PDMS as a function of the elongation.

For all tested CNT concentrations below $5 \%$ elongation, the resistance of the test structures has a plateau (marked as red line in Figure 4). Within the accuracy of the measurement the resistance can be considered as independent from the elongation up to this value. This was not the case for the test structures filled with $G$ that behaved similar to that shown in Figure 3 for all concentrations.
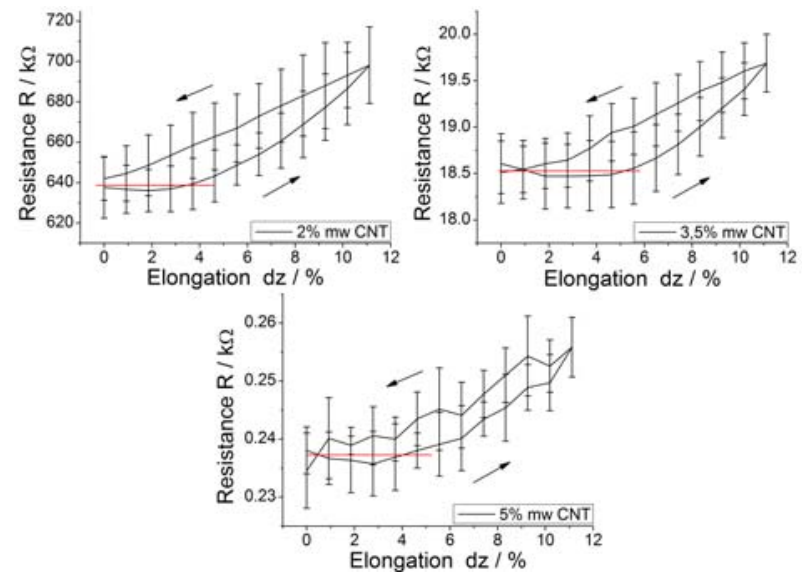

Figure 4: Resistance/elongation diagrams for different CNT concentrations. Plateaus are visualized as red lines.

\section{Discussion}

The different behavior of the $\mathrm{G}$ and $\mathrm{CB}$ test structures at elongation as seen in Figure 3 are probably a result of the different shapes of the filling particles. Conductive fillers with a flat structure $(G)$ produce a percolation network much easier than spherical particles (CB) [8]. Lengthening of the test structures segregates spherical particles. By reorientation platy particles may be able to avoid the applied stress, coming from the tapering perpendicular to the elongation. Thereby the percolation network can optimize its structure and build up new connections resulting in a decreasing resistance. According to [8] the percolation threshold for G should be smaller than that of CB. The quality of filling materials we used may be the reason that we could not reproduce this. Furthermore no segregation with sonication or other methods was applied. Therefore the particles aggregated and higher concentrations were needed for formation of percolation networks. Due to the structure of the CNT they form the best percolation network within the polymer. The addition of already $5 \mathrm{wt} \% \mathrm{CNT}$ produced a conductivity twice and ten times as good as the highest possible concentration of $\mathrm{CB}$ and $\mathrm{G}$, respectively. Due to the elongation independency of the resistance below $6 \%$, CNT are the best choice for replacement of metallic conducting paths in flexible implants.

\section{Acknowledgement}

This work was supported by the project elaN "Micro Nano integration as key technology for the next generation of sensors and actuators" (16SV5367), funded by the German Federal Ministry for Education and Research (BMBF).

\section{Bibliography}

[1] T. Stieglitz, "Flexible biomedical microdevices with double-sided electrode arrangements for neural applications," Sensors and Actuators A: Physical, vol. 90, no. 3, pp. 203-211, May 2001.

[2] K. P. Hoffmann, K. P. Koch, T. Doerge, and S. Micera, "New technologies in manufacturing of different implantable microelectrodes as an interface to the peripheral nervous system," in The First IEEE/RAS-EMBS International Conference on Biomedical Robotics and Biomechatronics, 2006. BioRob 2006, 2006, pp. 414-419.

[3] M. Aresti, N. Torres, and F. J. Gracia, "Planar Microelectrodes on Flexible Polymeric Substrates for Cochlear Implants," in 2007 Spanish Conference on Electron Devices, 2007, pp. 185-188.

[4] C. Hassler, T. Boretius, and T. Stieglitz, "Polymers for Neural Implants," Journal of Polymer Science: Polymer Physics Edition, vol. 49, pp. 18-33, 2011.

[5] A. Blau, A. Murr, S. Wolff, E. Sernagor, P. Medini, G. Iurilli, C. Ziegler, and F. Benfenati, "Flexible, allpolymer microelectrode arrays for the capture of cardiac and neuronal signals," Biomaterials, vol. 32, no. 7, pp. 1778-1786, Mar. 2011.

[6] D. Chung, "Flexible Conductive Polymer Electrodes for Applications in Tissue Electrical Impedance Scanning (EIS)," Masterarbeit, Simon Fraser University, Burnaby, 2012.

[7] DIN 53504, "Prüfung von Kautschuk und Elastomeren - Bestimmung von Reißfestigkeit, Zugfestigkeit, Reißdehnung und Spannungswerten im Zugversuch.” Deutsches Institut für Normung e.V., Oct-2009.

[8] J. Li and J.-K. Kim, "Percolation threshold of conducting polymer composites containing 3D randomly distributed graphite nanoplatelets," Composites Science and Technology, vol. 67, no. 10, pp. 2114-2120, Aug. 2007. 